\title{
História da psicologia: indivíduos, instituições e institucionalizações
}

\section{History of psychology: actors, institutions and institutionalization}

Historia de la psicología: personas, instituciones y institucionalización

\author{
Ana Maria Del Grossi Ferreira Mota* \\ Universidade Católica Dom Bosco - UCDB, Campo Grande, Mato Grosso do Sul, \\ Brasil
}

\section{Bianca dos Santos Cara**}

Universidade Católica Dom Bosco - UCDB, Campo Grande, Mato Grosso do Sul, Brasil

\section{Rodrigo Lopes Miranda***}

Universidade Católica Dom Bosco - UCDB, Campo Grande, Mato Grosso do Sul, Brasil

Jacó-Vilela, A. M., \& Portugal, F. T. (Org.). (2014). Clio - Psyché: Instituições, Histórias, Psicologia. Rio de Janeiro: Outras Letras. $324 p$.

Nas últimas décadas, a História da Psicologia tem se fortalecido como um campo especializado na I beroamérica, no âmbito geral e no Brasil, especificamente. Um exemplo disso é a formação de sociedades específicas, tais como a Rede Iberoamericana de Pesquisadores em História da Psicologia (RIPeHP) e a Sociedade Brasileira de História da Psicologia (SBHP). Além disso, nota-se tal fortalecimento a partir de um crescente contingente de produções, com uma pluralidade de temáticas. O livro Clio-Psyché: Instituições, História, Psicologia constitui um exemplo desse fortalecimento. Sua leitura é indicada aos que se interessam pela História da Psicologia, como campo de pesquisa. Além disso, ele se tornou um rico material de ensino nos cursos de Psicologia, em níveis de graduação e pósgraduação.

O livro é composto por reflexões e debates realizados no $X$ Encontro Clio-Psyché - Instituições, Psicologia, História, e compreende 
quatorze capítulos divididos em quatro sessões, a saber: (1) indivíduos e instituições; (2) aproximações e diferenças da institucionalização da Psicologia, na Argentina e no Brasil; (3) Psicologia na Argentina e (4) depoimento de Celso Pereira de Sá, importante figura do curso de Psicologia, da Universidade do Estado do Rio de Janeiro (UERJ).

$\mathrm{Na}$ primeira parte do livro vislumbramos transformações na Psicologia, a partir de um viés biográfico disposto cronologicamente, em que se aborda diferentes países (p.ex.: Brasil, Espanha, Portugal) e também diferentes autores (p.ex.: Emilio Mira y Lopez, Eliezer Schneider, Waclaw Radecki). A seleção de tais autores nos ajuda a entender não apenas suas contribuições locais, como no caso da Psicologia brasileira, mas, também, as conexões interculturais. Mira y Lopez, por exemplo, atuou na Espanha, no Brasil e em vários países da América Latina. Radecki, por sua vez, estudou em Genebra, além de trabalhar no Brasil e em países latino-americanos. O destaque nas conexões interculturais tem sido um ponto importante em debates contemporâneos, na História da Psicologia (ver Pickren, 2009). A abordagem biográfica tem se fortalecido, na historiografia geral, na história das ciências e também na história da Psicologia. Nesta perspectiva, procura-se compreender as características de um período histórico, pelo estudo da biografia de pessoas, como no caso do capítulo três, no qual se expõem aspectos da contribuição de Radecki à Psicologia brasileira e os aspectos sociais concernentes à sua prática científica, apontando elementos que indicam sua dificuldade nos relacionamentos interpessoais, sociais e políticos. Ressalte-se que ele era considerado, muitas vezes, um "non sense" (Centofanti, 2014).

$\mathrm{Na}$ segunda parte do livro, os textos contam com a escrita de brasileiros e argentinos abordando semelhanças e diferenças nos mecanismos de institucionalização e saberes e práticas psicológicas, em diferentes países. Esse tipo de abordagem crítico-comparativa também é frequente nas produções iberoamericanas. Em um número especial sobre história da Psicologia, da revista colombiana Universitas Psychologica, são variados os artigos dentro de tal perspectiva (p.ex.: Piñeda \& Jacó-Vilela, 2014). O décimo capítulo de Hugo Klappenbach (2014), por exemplo, apresenta a história da institucionalização da Psicologia, na Argentina. Ele versa sobre a construção de sociedades científicas e como, ao longo do tempo, elas deram lugar a associações profissionais, especialmente a partir da década de 1960, com o surgimento dos primeiros profissionais graduados em cursos de Psicologia.

$\mathrm{Na}$ terceira parte do livro, é possível verificar três textos de autoras argentinas. As autoras enfatizam aspectos diferentes da história da Psicologia argentina. Notam-se textos que abordam desde a gênese de instituições vinculadas à Psicologia, até a recepção de teorias, a 
partir de conceitos específicos. Além disso, percebem-se capítulos com influências metodológicas bem atuais em História da Psicologia, como a sociobibliometria. Mais uma vez, podemos notar a conexão das produções iberoamericanas com aquilo que tem sido pesquisado alhures. Essas temáticas como, por exemplo, a história a partir de conceitos específicos, já vêm sendo trabalhadas tanto na história das ciências quanto na história da Psicologia (Danziger, 2003). No campo de influências metodológicas, situa-se o capítulo assinado por Piñeda (2014). Nele, a autora investigou publicações e coleções que formaram os conteúdos de cursos de graduação em Psicologia, entre 1957 e 1982. Ela mostra variação no percentual de obras traduzidas, docentes que também foram autores de obras, etc, a partir de tabelas com programas de disciplinas, características da formação em Psicologia, na Argentina.

Há detalhes no livro que precisariam de melhores arremates, embora já se apresentem como características promissoras. Ao longo dele, observa-se que alguns textos são comentados por outros autores. Tais comentários se apresentam de forma crítico reflexiva, contribuindo para a leitura do texto comentado. Entretanto, como apenas três capítulos foram comentados, pairam algumas dúvidas: Como foi feita a seleção de três textos do livro para tais comentários? Por que nem todos são comentados? De toda forma, a criação de uma seção para comentários e debates é potencialmente proveitosa para o leitor interessado em aprofundamento no campo. Estima-se que este recurso seja utilizado novamente, em futuras publicações dos organizadores.

Diante disso, o livro Clio-Psyché: Instituições, História, Psicologia proporciona um olhar sobre a história da Psicologia por meio de indivíduos, institutos e instituições. Favorece a leitura, com comentários feitos a alguns capítulos. Apresenta-se bem estruturado, mostrando capítulos adequados a seus objetivos. Por fim, a história da Psicologia é apresentada de forma diversa e como um campo que ainda tem muito a ser explorado.

\section{Referências}

Centofanti, R. (2014). Teoria, método e aplicação na obra de Waclaw Radecki. In A. M. Jacó-Vilela, \& F. T. Portugal (Orgs.), Clio Psyché: Instituições, histórias, psicologia (pp. 59-70). Rio de Janeiro: Outras Letras.

Danziger, K. (2003). Where history, theory, and phylosophy meet the biography of psychological objects. In D. B. Hill, \& M. J. Krall (Orgs.). About psychology: Essays at the crossroads of history, theory, and philosophy (pp. 19-33). Nova Iorque: New York University Press. 
Klappenbach, H. (2014). Institucionalização da psicologia na Argentina: Das sociedades científicas às associações profissionais. In A. M. Jacó-Vilela, \& F. T. Portugal (Orgs.), Clio Psyché: Instituições, histórias, psicologia (pp. 220-246). Rio de Janeiro: Outras Letras.

Pickren, W. (2009) Indigenization and the history of psychology. Psychological Studies, 54(2), 87-95.

Piñeda, M. A. (2014). Modelos de psicologia e perfis de psicólogos na UBA e na UNLP. Incidência de publicações e editoras em cursos introdutórias à psicologia: 1957-1982. In A. M. Jacó-Vilela, \& F. T. Portugal (Orgs.), Clio Psyché: Instituições, histórias, psicologia (pp. 279-304). Rio de Janeiro: Outras Letras.

Piñeda, M. A., \& Jacó-Vilela, A. M. (2014). Ciencia psicológica y professionalización en Argentina y Brasil: 1930-1980. Universitas Psychologica, 13(5), 2015-2033.

\section{Endereço para correspondência}

\section{Ana Maria Del Grossi Ferreira Mota}

Universidade Católica Dom Bosco - UCDB

Av. Tamandaré, 6000, Jd. Seminário, CEP 79002-367, Campo Grande - MS, Brasil

Endereço eletrônico: amdelgrossi@gmail.com

\section{Bianca dos Santos Cara}

Universidade Católica Dom Bosco - UCDB

Av. Tamandaré, 6000, Jd. Seminário, CEP 79002-367, Campo Grande - MS, Brasil

Endereço eletrônico: biancacara@gmail.com

\section{Rodrigo Lopes Miranda}

Universidade Católica Dom Bosco - UCDB

Av. Tamandaré, 6000, Jd. Seminário, CEP 79002-367, Campo Grande - MS, Brasil

Endereço eletrônico: rlmiranda@ucdb.br

Recebido em: 11/12/2015

Aceito para publicação em: 14/01/2016

\section{Notas}

* Mestranda em Psicologia pela Universidade Católica Dom Bosco (UCDB). Professora da Universidade para o Desenvolvimento do Estado e da Região do Pantanal (Anhanguera-UNIDERP).

** Mestranda em Psicologia pela Universidade Católica Dom Bosco (UCDB). Professora da Faculdade Mato Grosso do Sul (FACSUL).

*** Doutor em Educação pela FaE-UFMG. Professor do Programa de Pós-Graduação em Psicologia da Universidade Católica Dom Bosco (UCDB). 